\title{
The Effectiveness of Creating Localized Content for Middle School Computing Curriculum
}

\author{
Huda Gedawy \\ Computer Science \\ Carnegie Mellon University Qatar \\ Doha, Qatar \\ hgedawy@cmu.edu
}

\author{
Saquib Razak \\ Computer Science \\ Carnegie Mellon University Qatar \\ Doha, Qatar \\ srazak@cmu.edu
}

\author{
Hanan Alshikhabobakr \\ Computer Science \\ Carnegie Mellon University Qatar \\ Doha, Qatar \\ halshikh@cmu.edu
}

\begin{abstract}
The need for computing education in $\mathrm{K}-12$ is growing all over the world. Several countries have created national curriculum standards to meet this growing need. In most cases, the actual implementation of the curriculum, including the technical content, is left to individual schools or teachers. In this paper, we outline our work in implementing a computing curriculum based on Alice software in the State of Qatar. We present our experience in creating the content and evaluating its effectiveness. The curriculum was developed in cooperation with schoolteachers, education professionals, and the Qatari Ministry of Education. Materials developed included lesson plans, academic calendar, assessment tools, and student textbooks. We address the issues encountered in creating this computing curriculum content.
\end{abstract}

\section{CCS Concepts}

- Computing education • Critical thinking

\section{Keywords}

Curriculum Content, K-12, Computing, Computer Science

\section{ACM Reference format:}

Huda Gedawy, Saquib Razak, and Hanan Alshikhabobakr. 2019. The Effectiveness of Creating Localized Content for Middle School Computing Curriculum. In Proceedings of 24th Annual ACM Conference on Innovation and Technology in Computer Science Education (ITiCSE'19), July 15-17, 2019, Aberdeen, Scotland, UK. ACM, NY, NY, USA, 7 pages. https://doi.org/10.1145/3304221.3319778

\section{INTRODUCTION}

The importance of computational thinking has pushed many countries to introduce computing education at an early stage in their educational systems. Although the approach varies in different countries, many have recently included Computer Science (CS) in their K-12 curriculum. The National Science Foundation (NSF) in the US, for example, funded CS $10 \mathrm{~K}$ to introduce computer science in 10,000 high schools, aiming to train

Permission to make digital or hard copies of all or part of this work for personal or classroom use is granted without fee provided that copies are not made or distributed for profit or commercial advantage and that copies bear this notice and the full citation on the first page. Copyrights for components of this work owned by others than the author(s) must be honored. Abstracting with credit is permitted. To copy otherwise, or republish, to post on servers or to redistribute to lists, requires prior specific permission and/or a fee. Request permissions from Permissions@acm.org. ITiCSE '19, July 15-17, 2019, Aberdeen, Scotland UK

(C) 2019 Copyright is held by the owner/author(s). Publication rights licensed to ACM. ACM ISBN 978-1-4503-6301-3/19/07...\$15.00

https://doi.org/10.1145/3304221.3319778 more than 10,000 teachers to prepare them to deliver the program [1]. The Department of Education in the UK also introduced their new National Curriculum in 2014, requiring K-12 to teach computing in place of the Information and Communications Technologies (ICT) curriculum. Similarly, countries like New Zealand and France have started to shift from using ICT curriculum to using CS [2] [3]. Some countries such as Poland, Korea and Germany started this process even earlier by introducing CS in K-12 more than 30 years ago [4] [5].

The success of a curriculum depends on three main factors: well-designed standards that the curriculum needs to fulfil, curriculum content that matches the standards, and proper teacher training in curriculum content and pedagogy. Computer science education researchers and education boards in various countries have spent considerable effort in defining appropriates standards in computer science and computing for middle- and high-schools. There also seems to be an understanding that most teachers lack the necessary skills to teach computer science and hence a substantial emphasis has also been placed on training the teachers to deliver these standards. Unfortunately, while there is sufficient literature in designing curricula and guidelines for CS education in $\mathrm{K}-12$, there is a lack of support in the implementation of the new curricula in schools. Most of the existing work focuses on training teachers on the new tools but not assisting them in implementing the new content in a classroom setting. This results in placing the responsibility of content creation to teachers who are themselves not proficient in the field [6]. "It's really hard to convince a computer science professional to give up a job that pays up to three times more to pursue teaching" [7].

This lack of curriculum content has created difficulties for implementation and adaptation of computer science curriculum in schools [6]. The problem is more pronounced in countries where the medium of education is in languages other than English. In those countries, learning a concept as hard as programming, in a language other than the native language of the students introduces a severe cognitive overload on the students [8]. In most cases, teachers use English content with in-class explanations given in local languages [9]. The lack of online resources and textbooks in local languages cause a problem for both students and teachers [8].

Qatar is a small but resourceful country in the Middle East located in the Persian Gulf. The country's educational vision is in line with the international call to improve computing education [10]. Alice in the Middle East is a project that introduces computing education in Qatar. Throughout the last several years, this project focused on developing a computing curriculum based on the Alice programming environment [11]. Our efforts included creating a culturally relevant version of the Alice tool, collaborating with schools and the Ministry of Education (MOE) to 
design a suitable computing curriculum, and running professional development to better prepare teachers for course delivery. As mentioned earlier, there is a disconnect between skills of local teachers and skills required to create curriculum content for Computer Science. The focus of this paper is to present our experience in working to bridge this gap. As part of this project, we worked with teachers to create a suitable CS content in Arabic and English.

In this paper, we present our experience implementing an Alice-based CS curriculum in an effort to empower students and motivate them to consider computing for their higher education and future careers. We present our experience in developing the curriculum content and report on our findings based on feedback from students and teachers, as well as students' assessments. We focused on creating curriculum content that was readily usable by teachers after we had provided them with training. We created lesson plans for each class, assessment techniques and tools, textbooks for students and teachers, and online content for student support. We also present the challenges we faced in presenting the content in Arabic while keeping a connection with the equivalent English terminology. We measured the effectiveness of our approach by evaluating student satisfaction and enhancement in their computing knowledge and performance.

\section{LITERATURE REVIEW}

A recent report published in ACM's Transaction on Computing Education journal summarized the experience of five countries that implemented CS in their K-12 schools [2]. Each of these cases reported their experience following Darmstadt framework, which was developed to allow a more practical way of transferring research results in the field of CS education [12]. Even after reviewing the case studies, questions about how to design effective curriculum still remain: "How should CS school curricula be designed? Which structure should CS school curricula have? How detailed should CS school curricula be? Who should be involved in the design process of CS school curricula?" [12]. In a study attempting to examine the role of $\mathrm{CS}$ and its rationales in curricula, the members of the Task Force of the Education Committee (TC3) of the International Federation of Information Processing (IFIP) concluded that most countries in their study emphasized the need for K-12 students to learn CS [13]. Moreover, this study found that more investigation on teaching methods is needed as there is inadequate information on "how students learn to think computationally and how approaches developed in one curriculum area or context may become generalized to other areas" [13].

Examining CS curriculum implementation cases from several countries, we summarize prominent cases in France, New Zealand and Australia. The France Superior Curricula Council proposed new curricula that teach computational thinking for kindergarten, elementary and middle school students. In their first pilot study, they focused on K-5 STEM subjects that also involved CS topics inspired from the Computer Science Teachers Association (CSTA) [3]. New Zealand has recently implemented a computing curriculum in high schools to include not only teaching programming, but key ideas such as algorithms, human-computer interaction, and computer graphics [2]. They introduced CS for grade 8, where they developed their curriculum based on Englishlanguage published curricula like CSTA, European Digital Competence framework (DIGCOMP), APCS course, England national curriculum, and the Australian curriculum [14]. In
Australia, the curriculum was newly introduced in schools and was not purely taught as CS, but rather digital technology as a whole discipline. They attempted to balance computational thinking and human interaction with technology. They also aimed to make students well rounded users and creators of technology. This curriculum starts as early as kindergarten: "This curriculum assumes that students, even as young as five, have the capacity and the right to develop the skills and knowledge required to operate effectively and ethically in a digital world" [15].

Countries with a history of teaching CS may have struggled in retaining students, since students were not selecting the subject when offered as an elective; hence, such countries are considering reforming their curricula. Poland has had informatics in high school as an elective since 1986, but with low attendance. In their new curriculum published in 2015, they start with a clear description and course objectives that are adequately formulated to match the students' level. The curriculum will assist students in learning computational thinking in order to solve problems in various school subjects, as well as motivate students to consider computing as a career option. The new curriculum is flexible, allowing teachers to personalize the subject according to the student's level and interest [5]. Korea is another example, with a long history of implementing CS curriculum in schools. Their CS course was offered as a core subject in elementary and an elective in middle and high school as early as 1970. The curriculum incorporated unplugged activities and educational programming languages that rely less on syntax and Robotics. However, in the last 10 years, CS courses have had a high dropout rate in middle and high school and educators are now working on future plans to increase students' turnout [4].

\section{CURRICULUM DEVELOPMENT AND IMPLEMENTATION}

We found that supplying schools with the Alice tool and providing teachers with appropriate training was not sufficient to ensure students will acquire consistent knowledge and skills needed in computing. The MOE highly recommended that students and teachers were offered supportive materials based on their vast experience with teaching ICT in schools. Such materials included year and term plans, lecture notes, class activities, and assessments. The materials were developed in cooperation with teachers and were used as a guide to use Alice effectively in delivering the course. We observed that we could not rely on teachers to create the content since most teachers, although trained in IT fields, have been teaching computer applications for several years and are out of touch with computing and programming.

We began our process by articulating the major objectives and learning outcomes, i.e. what we want students to learn by the end of the academic year and/or term. We then created year and term plans for each week. The academic year was divided into two terms of 15 weeks. Classes met twice a week for 45-minute blocks. Students completed their assessments in weeks 14 and 15. Tables 1 and 2 show the distribution of Alice-based curriculum topics over the academic year. The sequence of topics was a major concern, since it influenced students' learning and engagement. We took extra care to make sure we alternated topics between a CS 
principal and Alice's features (sounds, cameras movement, etc.) that will bring the excitement back to the course.

For each concept, we created a PowerPoint presentation that teachers can use in classes, as well as a lesson plan and class activities. The lesson plans were created in close coordination with teachers in order to create activities appropriate for all students including the gifted and talented (G\&T), as well as, Special Education Need (SEN) students. Lesson plans started with an overview of the lesson, and then presented the theoretical part by introducing the new concept. This was followed by an example of how the concept is applied and used to solve problems. Finally, the practical part of the lesson provided an example of the new concept in Alice animation. Students then used the new concepts for ideas of their own. Teachers were provided with solutions to all examples, exercises, sample short quizzes and tests. Students, on the other hand, were given study guides to help them prepare for exams. Each lesson was kept short enough for teachers to cover the activities during one class period. All content is available online at alice.qatar.cmu.edu.

\section{Table 1: Term 1 Schedule}

\begin{tabular}{|lc|}
\hline Week & Topics \\
\hline 1 & Introduction to computing \\
$2-3$ & Introduction to Alice and Alice controls \\
$4-5$ & Sequential and concurrent execution \\
6 & Adding text and using objects' properties \\
7 & Revision and midterm \\
$8-10$ & Storyboarding \\
11 & Using built-in functions and expressions \\
$12-13$ & Using camera and sound in Alice \\
$14-15$ & Students' project and final \\
\hline
\end{tabular}

Table 2: Term 2 Schedule

\begin{tabular}{|lc|}
\hline Week & Topics \\
\hline 1 & Recap, project simulation \\
$2-4$ & Program decomposition, writing and using methods \\
$5-6$ & Interactive programming and event handling \\
$7-8$ & Boolean expressions and conditional execution \\
9 & Revision and midterm \\
$10-11$ & Repetition and randomization \\
12 & Creating, applying and using parameters in methods \\
$13-14$ & Creating functions and variables \\
15 & Students' project and final \\
\hline
\end{tabular}

\subsection{Piloting Stage}

We introduced a computing curriculum for middle school students in Qatar that uses Alice as a tool to introduce complex programming concepts in a more accessible and engaging way. We began our collaboration with three schools (2 public schools and 1 private) in 2014-2015. More than 320 students in grade 8 used the Alice tool and the curriculum materials during ICT classes taught twice a week for 1 hour per session.

\subsection{Assessment Plan}

One of our major objectives was to evaluate the effectiveness of this approach with participating teachers and students. Data was collected from teachers and students in surveys. Teachers answered questions relevant to their own experiences with Alice and the curriculum materials, as well as student experiences from the teachers' perspective. For instance, we asked teachers about their experience in teaching computing, including which topics students enjoyed more and if students understand the explanations provided in the materials or do they need clarification. We also asked teachers what would they change in the curriculum, as well as what other suggestions they might have. Students were asked to evaluate the curriculum by rating their experiences with the different topics. We also asked: what would they like to learn more of; what were questions they asked their teachers that were not answered; which examples did they like more; and what difficulties did they face.

Teachers submitted feedback form at the end of each class. The data was used to evaluate the quality and suitability of the lessons and in identifying shortcomings, support mechanisms needed, and areas of improvement. Teachers answered questions about difficulties faced in teaching a topic; what worked well and what did not; did students display interest in the demonstration and exercises; and how many students finished the exercises successfully. Furthermore, we administered pre- and post-tests to targeted students to assess progress in learning logic, computational thinking, and problem-solving skills. This data was used to measure the effectiveness of the curriculum and guide revisions.

During the evaluation of the pilot-testing stage of the curriculum, we conducted school visits to get first-hand impressions of the progress. We attended classes to understand students' overall experience and to identify the extent of the usability of materials provided to teachers.

\section{CURRICULUM IMPROVEMENTS}

The feedback collected in the pilot stage helped us improve the quality and suitability of the curriculum, as well as to create an appropriate textbook. In light of the lessons learned and recommendations from the $\mathrm{MOE}$ and teachers, we found it necessary to offer students a textbook to facilitate their learning and enable them to have a better early CS education experience. Tailored textbooks were developed because of lack of suitable CS resources that accommodate for course type, as well as preserve culture and social values. Therefore, we wrote textbooks in Arabic for middle school students who were taking Alice as a regular subject. The textbook content was made to be modern, familiar and culturally acceptable by students in Qatar. Each chapter in the book included: an introduction, learning objectives, a definition and explanation of the concept, technical terminologies and some hints about designing and developing techniques. Flowcharts were developed to show how advanced programming statements execute, in addition to solved examples that promoted good programming habits. Each chapter ended with a summary of terms, a number of theoretical questions, and some practical exercises that students should be able to complete on their own.

The Arabic textbook had to be mindful that students use Alice, as a tool, in English. Furthermore, university-level computing studies are conducted in English, hence, students should be familiar with English terminology used in computing concepts. Our Arabic textbook incorporated English terminology wherever appropriate. An example of a typical book chapter is shown in figure 1. 


\section{CURRICULUM CHALLENGES}

Initiating a computing curriculum based on students' creativity and ability was a difficult task. The curriculum was created and improved as a result of the feedback; however, it aimed to make a difference in the quality of CS education in Qatar and integrate well in schools. The lack of resources to teach CS concepts in the medium of instruction being used at the schools was a major challenge. It was also difficult to secure teacher buy-in due to a lack of trust in new materials and resistance to change. Teachers found it difficult to cope with some pedagogical and conceptual challenges in teaching Alice. Below is a list of main challenges experienced while developing and improving the curriculum.



Figure 1: English vocabulary for key concepts embedded within the Arabic textbook.

\subsection{Reading Level}

We intended to present the concepts at an appropriate reading level so that middle school students could understand, follow and absorb the content easily. We also had to guarantee the suitability of the language and vocabulary selection for the target age group. We followed the approach of using real life analogies, since this is a good way to introduce advanced CS concepts. We provided examples of how the concepts exist in our daily life and looked at how to apply them to solve problems in the different aspects of life. For instance, the typical walking action we repeat everyday includes sequential and concurrent actions of taking one step at a time and moving legs and arms simultaneously. Students can model these actions, thus facilitating learning and recognition of the concepts. To ensure appropriateness of textbook content, we checked the clarity of language and selection of vocabulary with English and Arabic language experts and we reviewed the overall curriculum content in consultation with university curriculum consultants, MOE\&HE and CS professors. Subsequently, we tested sample chapters on students and collected feedback before the widespread use of the curriculum in the field-testing stage.

\subsection{Content Translation}

It was critical to provide Arabic speaking students with a learning resource in their native language to relieve the cognitive overload of studying CS in a foreign language. We created an Arabic version for all curricular materials and the challenge was mainly in translating computing terminologies into Arabic. English is the language of technology and the language of computing and programing, hence, the computing terminology in other languages, including Arabic, is poor and not found in professional literature. We found research on computer science terminologies in Arabic to be inconvenient and not standardized.

In a study done on the vague use of computer linguistics when translated into Arabic, Khuwaileh contextualized a number of common and heavily used computer terms that have no equivalence in Arabic [16]. Their study showed that many computer terms are problematic and are classified as vague expressions and terminologies. For example, compute and calculate are translated as having identical meanings, and descriptive statistical words like mean, simultaneous and critical value were inappropriately translated in computer textbooks [16]. Furthermore, Khuwaileh found that problematic words were hard to translate because of the lack of Arabic translation resources in the computer field as well as the inefficiency of the English-Arabic dictionaries.

When translating the materials, we ensured an accurate delivery of the information while maintain a commitment to the source and target languages. The language of instruction must be clear, concise and precise. Terminologies such as loops, if/else conditions, functions, variables and modularity lost their real meaning when translated into Arabic. We needed to have a sense of language perception in order to select the most suitable term from the Arabic dictionary. In cases where no equivalence was available, we provided an explanation of the concepts as required. Also, when a denotative meaning did not express the concept well, we offered a connotative meaning. The vocabulary selection was reviewed with language exports and English terminologies were kept in the book to enrich students' computing dictionary.

\subsection{Content Suitability}

Qatar is a conservative country that values the preservation of religion, heritage, and tradition. To guarantee acceptance, a culturally and religiously appropriate curriculum was as important as making it academically strong. Contextualizing the materials can have a significant impact in students' attainment and interest, as well as teachers' efficacy. For instance, using examples that reflect the local environment like camel racing and pearl diving made the content more engaging for students and enabled them to absorb materials better. Moreover, we could not use examples asking students to calculate monetary amounts with nickels and dimes, since students are not familiar with the terms.

\section{FIELD TESTING STAGE}

Following the successful piloting of Alice curriculum in three schools, we expanded our attempts to reach more schools. In academic year 2015-2016, we collaborated with 11 schools with more than 800 students.

\subsection{Implementation Plan}

In this stage, students from six public schools and five private schools used the textbooks and study guides. Teachers used the 
improved supportive materials including term plans, lesson plans, and quizzes. Teachers followed the same pedagogical technique as in the pilot stage and introduced new concepts through storytelling. To create animations or games in Alice, students had to logically decompose the problem, develop the algorithm, and implement the code. This technique proved to work well with students, since it simplified challenging concepts like conditional execution and developed their computational thinking skills in an innovative context. Teachers also employed techniques to help students understand the importance of the concept before introducing it. For example, when students learn how to animate a cat jumping, the first comment they made was "it's jumping only once" or "how can we duplicate the action?" Most students followed the simple approach of copying and pasting the jumping code several times. At that point, teachers presented the looping concept and students understood it better [17].

\subsection{Assessment Plan}

Towards the end of the academic year, we evaluated the curriculum implemented in the field-testing stage in public schools in which around 460 students were involved in the study. In this process, we analyzed feedback collected from teachers and students (Satisfaction Indicators) and improvements in students' computational thinking, logical reasoning, and analytical skills (Performance Indicators).

We conducted a one-hour focus group interview in all six public schools asking teachers questions about their overall experience as well as their perceived students' experiences. Teachers completed surveys about their personal experience teaching programming and computing, and this curriculum in particular. Students answered surveys and assessments to report on their general experience with the program and curriculum materials, as well as improvements in their attainment levels.

\section{FINDINGS}

Data collected in the pilot and field testing stages were compiled, encoded, compared and analyzed to give us insight into the current status of the program and its future direction. The major objective of collecting this data was to evaluate and prove the effectiveness of our approach in building computing knowledge and skills, while keeping students' interest. It is important to clarify that student surveys and assessments were sent to schools and teachers were asked to encourage students to complete them. We, therefore, had no control over the quantity of responses.

\section{1 Satisfaction Indicators}

Teachers' and students' satisfaction indicators were measured using feedback on their overall experience and the course contents. Comments collected from teachers, in the interviews and surveys, were coded and classified under three categories; 1) Positive: something good about the program [i.e. Students liked the book], 2) Negative: a short coming of the program [i.e. It was targeting higher achievers] and 3) Challenge: something negative beyond the program [i.e. Students were not introduced to programming before]. Students' responses, in the anonymous surveys, were also coded and divided into two categories; positive (very satisfied and satisfied) and negative (not satisfied and not satisfied at all).
Table 3: Students' Ratings of the Book's Evaluation Criteria

\begin{tabular}{ll}
\hline Criteria & $\%$ \\
\hline Contents of the book were suitable. & 60 \\
I could easily understand the concepts. & 63 \\
Concepts were introduced in an engaging way. & 62 \\
I was able to complete the examples with the teacher. & 64 \\
I could implement most of the exercises in Alice. & 55 \\
The level of exercises was suitable. & 62 \\
The level of questions was suitable. & 59 \\
I needed simpler explanation to understand the topics. & 51 \\
I needed more examples. & 51 \\
I liked the book design and organization. & 51 \\
The lesson time covered the content and/or exercise. & 53 \\
I contributed in class with questions and comments. & 60 \\
\hline
\end{tabular}

\subsubsection{Feedback on Overall Experience}

In focus group interviews, we asked teachers about their overall experience teaching the program, as well as their perceived students' experience. After analyzing the data, we found that $50 \%$ of their comments about the program were positive (i.e. some teachers described their experience by saying; "It was surprisingly positive; we didn't expect this. We were against it from the beginning since students are suffering with other ICT tools used already" and "It was difficult in general for the majority of students, however we found that it stimulated students' minds and provoked their creative thinking"). Around 15\% of teachers indicated facing some challenges (i.e. one of the teachers explained 'Students' major problem was their motivation to learn not their abilities to learn and work with Alice"). Overall, 35\% of the comments were negative, some of which were due to students' lack of interest in programming and the difficulty of the program. We hope that as teachers become more comfortable with teaching computing concepts, this negative sentiment will decrease.

Students were asked to report on their satisfaction with the program. Only 97 students replied to this question and $85 \%$ of those had positive responses about their experience - one student said, "Alice was interesting and easy for me, I only faced few difficulties," another said, "It was fun". Conversely, $15 \%$ of students' comments were negative - a student said, "Everything is hard in the program", another said, "The program is hard and not useful" while another explained, "Programming is hard". Complaining is culturally acceptable and encouraged in Qatar, therefore it is not surprising that students' complaints would be clearly communicated. In fact, the MOE\&HE has set up emails to accept complaints about schools. Therefore, an $85 \%$ positive result is a good indicator of success.

\subsubsection{Feedback on Course Content}

To assess the effectiveness of our computing curriculum, we asked teachers about the content suitability for students in that age group, as well as to comment on their overall experience using the book for teaching. Teachers had more negative comments about the book than positive. Some of the negative comments were: "The book was very heavy and big" and "The theory questions were too difficult". Most of their positive comments were associated with students - "Students liked the book and liked the interactive programming the most".

In evaluating their experience with the book, students were also asked about the content suitability and whether the main concepts and contents presented were easily understood. To 
analyze this part, we coded students' ratings and categorized them into positive: $>=3$ and negative: $<3$. In general, $57 \%$ evaluated the book positively, which signifies that students regarded the book as good. Most of the negative comments were associated with book's big size (i.e. one of the students said, "The book was long and one semester wasn't sufficient to complete it"). Please refer to table 3 for more details on student evaluation of the book. Although the majority of students were satisfied with the book, $51 \%$ felt they needed more examples and preferred simpler explanation in order to understand the topics.

Table 4: Teachers' Satisfaction Indictor with the Book

\begin{tabular}{lc}
\hline Indicator & Average Rating \\
\hline Overall experience with teaching Alice. & 3.2 \\
Students' overall experience with Alice. & 2.2 \\
Experience using the book to teach. & 2.6 \\
Topics presented in the book. & 2.5 \\
Examples and exercise in the book. & 2.6 \\
Students' use of the book. & 2.8 \\
Support to students during semester. & 3.3 \\
\hline
\end{tabular}

Although we collected data from focus group interviews, we felt it was important to collect data on teachers' individual perspectives about the program. We asked teacher to complete a survey rating their experience with the program and the curriculum. Teachers were given two rating scales of 1-4. We coded the data and categorized anything with a rating of $>2$ as positive. In particular, for questions 1-5 indicators were as follows: (1=poor, $2=$ good, $3=$ very good and $4=$ excellent) and for questions 6-7 (1=not at all, $2=$ somewhat, $3=$ mostly and $4=$ very much). As indicated in table 4 , on average almost all of the ratings were above 2, which implies that the teachers were satisfied with their experience and the materials in general.

\subsection{Performance Indicators}

Student and teacher satisfaction for the program and curriculum was not sufficient to indicate the success of this initiative: an evaluation of the curriculum's quality was mandatory. We conducted pre- and post- assessments for a randomly selected group of 122 students to measure the growth in their level. The same assessment was given to a group of students of same age who took existing ICT curriculum. The schools in the second group were selected randomly by Ministry of Education. The students were required to complete the assessment during regular lessons. The assessments consisted of 15 multiple-choice questions that required no special knowledge other than thinking abilities. Students used computational and algorithmic thinking skills to analyze problems in the test and drive conclusions. In general, Alice students were able to demonstrate higher levels of logical thinking and analytical skills. The results showed that Alice students scored $7.5 \%$ higher on average than the control group. Furthermore, two Alice students scored above $70 \%$ on the assessment, compared to a highest score of $60 \%$ in the control group [18]. This result shows a lack of motivation for gifted and talented students while using the existing ICT curriculum.

\section{DISCUSSION}

Throughout the implementation phases of the program, we were able to collect data to help us measure the effectiveness of the curriculum. We discovered that there were more positive impressions of the curriculum materials. Students who were introduced to programming through Alice generally enjoyed the experience. Most students felt that the book had important subject matter and was relevant when applied in life. The fact that $60 \%$ of the students were contributing to lessons with comments and questions implies a high level of interest in the subject. Teachers also gave a rating of above 2 (good) for their experience with the curriculum, which means that they were comfortable teaching it. Although most of the teachers in the focus group interviews reported negative impressions about the book, it was mainly associated with the size and weight rather than the actual content.

In addition to the general positive impression received, the assessments results displayed improvements in students' computational thinking, logical reasoning, and analytical skills. The results also indicated that Alice students acquired more fundamental computing skills than the other group examined.

The findings proved our hypothesis that providing a culturally acceptable computing curriculum has a significant impact on increasing students' attainment and interest in computing and increasing teachers' interest in delivering more advanced CS courses, as per their request, which indicates its success.

\section{CONCLUSIONS AND FUTURE WORK}

Throughout our experience of making computing curriculum available in Qatari schools, we found that creating a tailored curriculum reflecting the local culture, language and age group of the target audience is the way forward. Creating a tailored curriculum also involved studying the educational context of Qatar that entailed assessing students' computing knowledge and teachers' experience with programing. The task was difficult to achieve considering there was no programming curriculum in place, in addition to the absence of suitable resources in teaching middle school students in Qatar.

Our future work will be to design and implement a computing curriculum that spans all three years of middle school. The curriculum will be designed with horizontal and vertical integration. This will ensure that learning is consistent with the skills that students have learned within their grade level, as well as, building on concepts incrementally across each successive grade. The curriculum will encourage inquiry based contextualized learning with design for transfer. More importantly, we will design and conduct teacher training that is intensive, on-going, and connected to practice to help teachers cope with the changes in the new computing curriculum.

\section{ACKNOWLEDGMENTS}

This paper was made possible by NPRP grant \# 10-0205-170345 from the Qatar National Research Fund (a member of Qatar Foundation). The statements made herein are solely the responsibility of the author[s].

\section{REFERENCES}

[1] M. desJardins, "Creating AP CS principles: let many flowers bloom," ACM Inroads, vol. 6, no. 4, 2015.

[2] T. Bell, P. Andreae and A. Robins, "A Case Study of the Introduction of Computer Science in NZ Schools," $A C M$ Transactions on Computing Education (TOCE), vol. 14, no. 2, p. 10, 2014. 
[3] V. Chiprianov and L. Gallon, "Introducing Computational Thinking to K-5 in a French Context," in ACM Conference on Innovation and Technology in Computer Science Education, 2016.

[4] J. Choi, S. An and Y. Lee, "Computing education in Koreacurrent issues and endeavors," ACM Transactions on Computing Education (TOCE), vol. 15, no. 2, p. 8, 2015.

[5] M. M. Syslo and A. B. Kwiatkowska, "Introducing a new computer science curriculum for all school levels in Poland," in International Conference on Informatics in Schools: Situation, Evolution, and Perspectives, 2015.

[6] K. Bateman, "The UK's new computing curriculum is here: Are teachers ready?," Computer Weekly, 082014.

[7] Z. Ahmad, "Filling the pipeline for computer science teachers," Science, 2019.

[8] S. Raj, A. Gerald, K. Ketsuriyonk, J. M. Patel and R. Halverson, "Does Native Language Play a Role in Learning a Programming Language?," in Proceedings of the 49th ACM Technical Symposium on Computer Science Education, New York, NY, USA, 2018.

[9] J. R. Fennema-Bloom, "Code-scaffolding: A pedagogic codeswitching technique for bilingual content instruction," Journal of Education, vol. 190, no. 3, pp. 27-35, 2010.

[10] "Qatar National Vision 2030," Qatar, General Secretariat for Development, 2008.

[11] S. Cooper, W. Dann and R. Pausch, "Alice: a 3-D tool for introductory programming concepts," In fournal of Computing Sciences in Colleges, vol. 15, no. 5, pp. 107-116, 2000.
[12] P. Hubwieser, M. Armoni and M. N. Giannakos, "How to implement rigorous computer science education in $\mathrm{K}-12$ schools? Some answers and many questions," ACM Transactions on Computing Education (TOCE), vol. 15, no. 2, 2015.

[13] M. Webb, N. Davis, T. Bell, Y. J. Katz, N. Reynolds, D. P. Chambers and M. M. Sysło, "Computer science in K-12 school curricula of the 2lst century: Why, what and when?," Education and Information Technologies , pp. 1-24, 2016.

[14] C. Duncan and T. Bell, "A Pilot Computer Science and Programming Course for Primary School Students," in Proceedings of ACM Workshop in Primary and Secondary Computing Education, 2015.

[15] M. Webb, N. Davis, T. Bell, Y. J. Katz, N. Reynolds, D. P. Chambers and M. M. Syslo, "Computer science in K-12 school curricula of the 2lst century: Why, what and when?" Education and Information Technologies, pp. 1-24, 2016.

[16] A. A. Khuwaileh, "IT terminology and translation: Cultural, lexicographic and linguistic problems," LSP Journal-Language for special purposes, professional communication, knowledge management and cognition, vol. 1, no. 2, 2010.

[17] N. Tabet, H. Gedawy, H. Alshikhabobakr and S. Razak, "From Alice to Python. Introducing Text-based Programming in Middle Schools.," in Proceedings of the 2016 ACM Conference on Innovation and Technology in Computer Science Education, Arequipa, 2016.

[18] S. A. Sabbagh, H. Gedawy, H. Alshikhabobakr and S. Razak, "Computing Curriculum in Middle Schools - An Expereince Report," in ACM Conference on Innovation and Technology in Computer Sceince Education, Bologna, 2017. 